\title{
RETROSPECTIVE STUDY OF DIFFERENT SURGICAL METHODS REQUIRED IN BENIGN MASS LESIONS OF THE NOSE
}

\author{
Parasuram G1, B. Nageswara Rao 2 , S. Suryaprakasa Rao 3 \\ ${ }_{1}^{1}$ Associate Professor, Department of ENT, Andhra Medical College, Visakhapatnam. \\ ${ }^{2}$ Assistant Professor, Department of ENT, Andhra Medical College, Visakhapatnam. \\ ${ }^{3}$ Professor, Department of ENT, Andhra Medical College, Visakhapatnam.
}

\section{ABSTRACT}

\section{AIM OF THE STUDY}

1. To plan surgical approaches in the treatment of the mass lesions of nose.

2. To develop infrastructure of District Headquarters Hospital.

\section{MATERIALS AND METHODS}

The study was conducted from January 2015 to March 2016 in Andhra Medical College, Government ENT Hospital, a Tertiary Referral Hospital in Andhra Pradesh. About 1,12,500 patients came from particularly 5 districts of Coastal Andhra Pradesh and also from Madhya Pradesh and Odissa in the above period of 15 months; 132 nasal surgeries like Functional endoscopic sinus surgery (95), Endoscopic assisted intranasal excision (24), Lateral Rhinotomy (6), Caldwell-Luc (5) and others were conducted to 132 ( $0.3 \%$ in the study group with nasal symptoms) patients with benign mass lesions of the nose for Nasal Polyposis, Juvenile Nasopharyngeal Angiofibroma, Inverted papilloma, Rhinosporidiosis and others which were identified among 43,940 patients that attended to outpatient department with nasal symptoms.

\section{CONCLUSION}

Functional endoscopic sinus surgery for nasal polyposis (71.96\%) has evolved to be the commonest surgical approach among the surgical methods used for treating benign mass lesions of the nose. Next comes the intranasal endoscopic assisted excision (10.6\%), later are Lateral rhinotomy, Caldwell-Luc, Weber-Ferguson's and simple external excision approaches in descending order for common lesions like Juvenile Nasopharyngeal Angiofibroma, Inverted Papilloma and rare tumours like Rhinosporidiosis, Fibrous dysplasia, Cerebral encephalocele and nasal dermoid.

\section{KEYWORDS}

FESS, Endoscopic Assisted Intranasal Excision, Mass Lesions of Nose, Nasal Polyps, Lateral Rhinotomy, Caldwell-Luc, WeberFerguson.

HOW TO CITE THIS ARTICLE: Parasuram G, Rao BN, Rao SS. Retrospective study of different surgical methods required in benign mass lesions of the nose. J. Evolution Med. Dent. Sci. 2016;5(58):4027-4030, DOI: 10.14260/jemds/2016/921

\section{INTRODUCTION}

After the invention of nasal endoscope and its usage in nasal surgery, the scenario of surgery to the nose is totally changed. The further assisting gadgets like HD cameras, LCD monitors and Microdebriders have modified the basic endoscopic surgical procedures.

The advent of CT scan, MRI scan, contrast enhanced studies and arteriography with embolization further overturned the surgical methods to the present status. The question of availability of the above gadgets and facilities will decide to elect the type of surgery in that hospital.

Until 1980, all the surgeries to the benign mass lesions of nose were treated with naked eye procedures by both intranasal and extranasal approaches. From 1990 after popularization of endoscopic usage, the techniques gradually changed to mostly intranasal approaches. Acceptance and availability of cadavers for dissecting courses further reduced the percentage of extranasal approaches. The cosmetic sense of patients made surgeons to change the route and to innovate techniques that avoid external surgical scars.

Financial or Other, Competing Interest: None.

Submission 10-06-2016, Peer Review 07-07-2016,

Acceptance 13-07-2016, Published 21-07-2016.

Corresponding Author:

Dr. S. Surya Prakasa Rao,

50-27-15/1,

Sitammadara N. E,

Visakhapatnam-530013.

E-mail:drssprao@gmail.com

DOI: $10.14260 /$ jemds $/ 2016 / 921$
Both external and internal approaches were used in benign tumours, various nasal polyps and prolapsed nasal masses are compiled. All the excised specimens were sent to the Department of Pathology to know the nature and histopathology.

Out of all the benign lesions of the nose, the nasal polyposis is the most common, hence functional endoscopic sinus surgery is evolved the commonest surgical procedure for benign mass lesions of the nose. ${ }^{1}$ The Endoscopic-assisted intranasal excision took the second position followed by Lateral Rhinotomy, Caldwell-Luc operation, Weber-Ferguson and simple external excision in descending order.

\section{MATERIALS AND METHODS}

This retrospective study was conducted in Government E.N.T Hospital, Andhra Medical College, which is a tertiary referral hospital in Visakhapatnam from January 2015 to March 2016, where about 250 patients attended outpatient department per day. The study was focused on sex difference, age variations, incidence of various tumours and finally the type of surgical procedure which is the aim of the present study. The nasal surgeries of this group aged between 2 yrs. - 73 yrs. with males affected more in number.

The number of patients who attended Govt. E.N.T. Hospital OPD, Andhra Medical College, a tertiary care centre was 1,12,500. Patients particularly came from 5 districts of Coastal Andhra Pradesh and also from Madhya Pradesh and Odissa.

The number of patients that presented with nasal complaints during the 15-month period from January 2015 to 
March 2016 was 43,940 (39.05\%); 132 nasal surgeries were performed on 132 patients who presented with mass lesions of nose; $(0.3 \%$ in the study group with nasal complaints).

\section{Inclusion Criteria}

1. Mass lesions arising due to Allergic, Fungal, Non-Specific and Specific infective pathology.

2. Benign tumours of nose.

3. Mass lesions of intracranial origin.

\section{Exclusion Criteria}

1. Malignant lesions of the nose.

2. Mass lesions of orbital origin.

3. Hypertrophied inferior turbinate.

4. Adenoid hypertrophy.

Anterior rhinoscopy with Bull's eye lamp was done to all the patients of the study group in Outpatient Department. Diagnostic nasal endoscopy in Examination OT, blood investigations, radiological investigations like X-ray, CT scan and MRI scan of Paranasal Sinuses were performed.

The surgical procedure of choice is preoperatively planned after group discussion of surgical team, based on the nature and extent of the tumour as per X-ray, CT and MRI. The excised tumour masses were sent for histopathology.

Suspected three cases of nasopharyngeal angiofibroma are removed after arterial angiography and embolization to reduce intraoperative bleeding.

Postoperative bleeding complication occurred in 3 cases, which was managed conservatively. ${ }^{2}$

\section{OBSERVATION AND RESULTS}

The total number of 1,12,500 patients were examined in the 15 months' period from January 2015 to March 2016. Around $43,940(39.05 \%)$ patients attended with nasal symptoms. The patients that presented with mass lesions of the nose were $132 ;(0.3 \%$ in the study group with nasal complaints).

\section{Sex Distribution}

\section{SEX INCIDENCE}

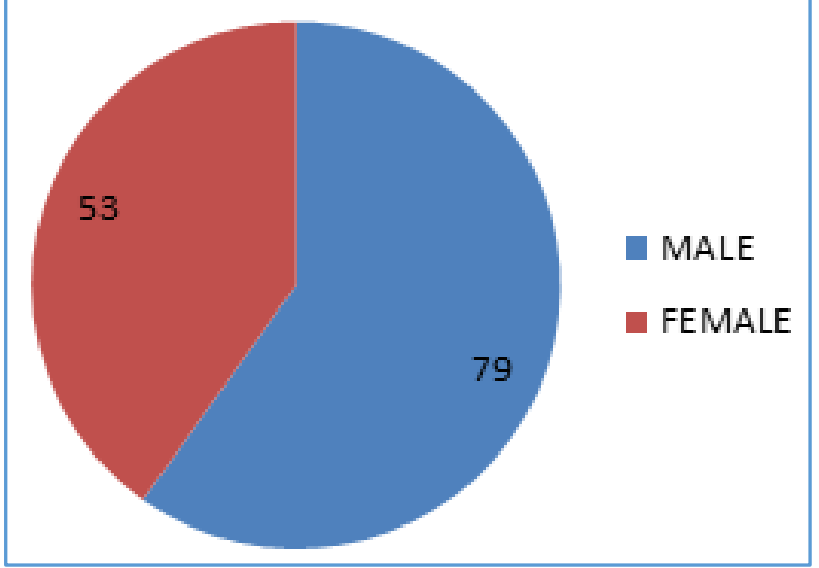

\begin{tabular}{|c|c|}
\hline Sex & Incidence \\
\hline Males & 79 \\
\hline Females & 53 \\
\hline
\end{tabular}

In the present study group which consisted of 132 patients, there were 79 males and 53 females which signifies male preponderance.

\section{Age Distribution}

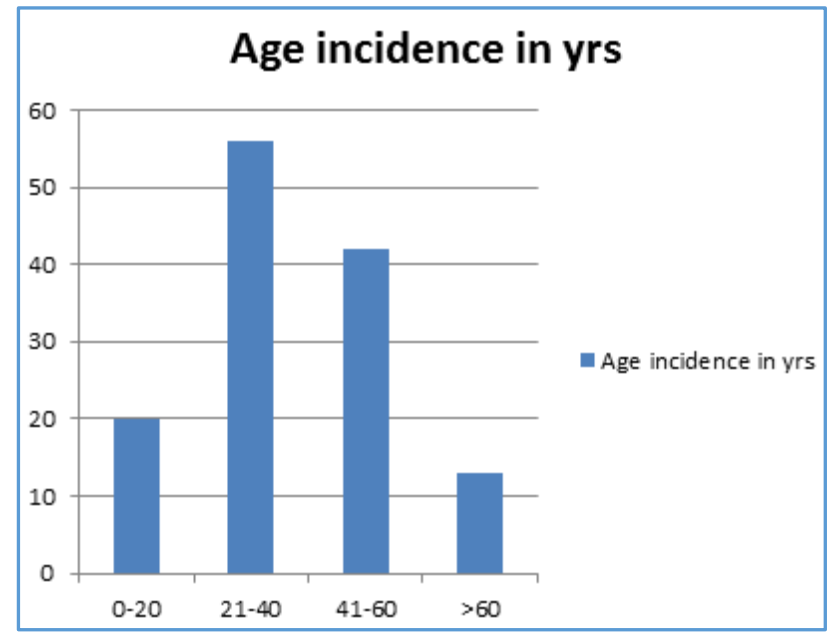

\begin{tabular}{|c|c|}
\hline Age Group in Years & Incidence \\
\hline $0-20$ & 20 \\
\hline $21-40$ & 56 \\
\hline $41-60$ & 42 \\
\hline$>60$ & 14 \\
\hline
\end{tabular}

In the study, 56 patients belonged to the age group 21-40 years, which was the commonest group affected accounting for $42.4 \%$, while the next common age group was $41-60$ years (31.8\%).

Out of 132 cases, 95 FESS Procedures were done to 95 cases of Nasal Polyposis

\begin{tabular}{|c|c|c|}
\hline Mass Lesions of the Nose & Number & Percentage \\
\hline Nasal polyposis & 95 & 71.96 \\
\hline Other mass lesions of the nose & 37 & 28.03 \\
\hline
\end{tabular}

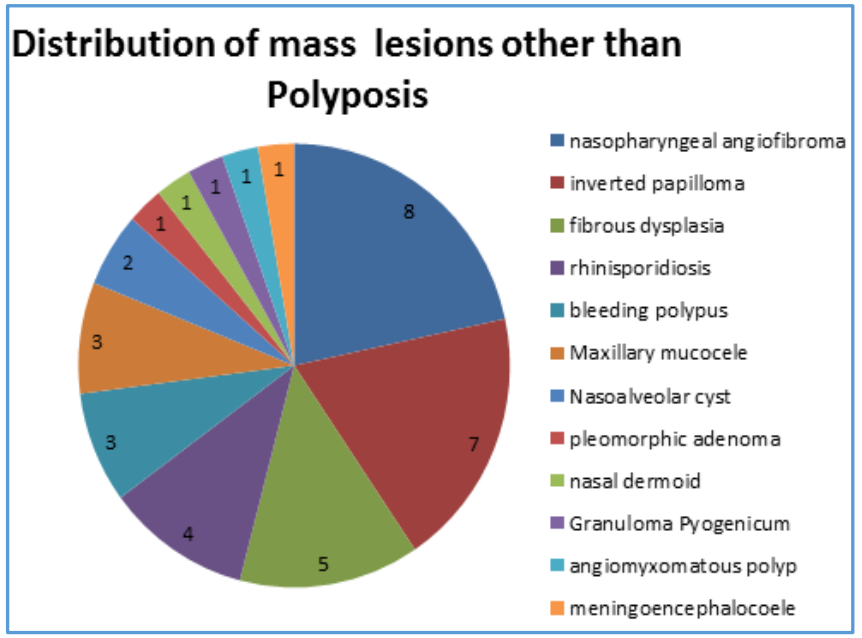




\section{Types of approaches}

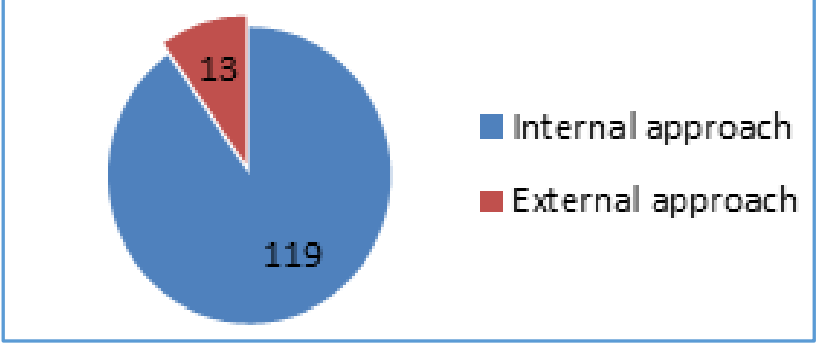

Among the 132 cases of the study, 119 (90.1\%) cases were treated by intranasal endoscopic approach, while 13 (9\%) were treated by external approaches.

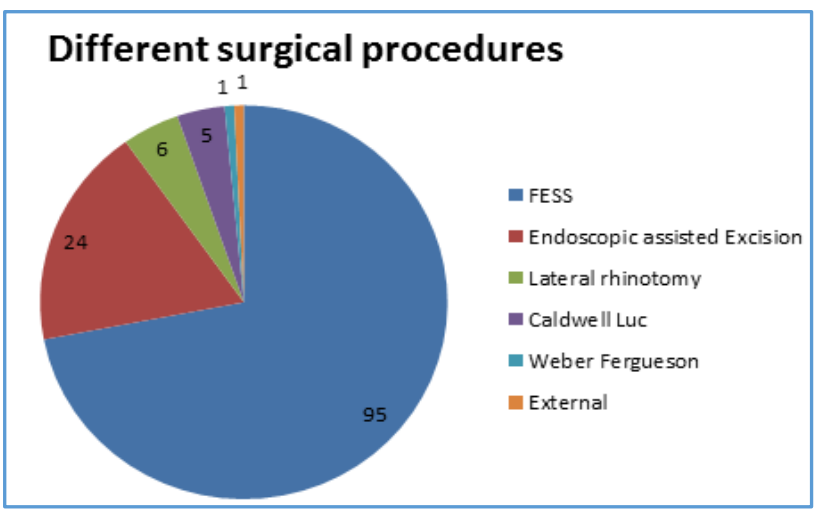

In this study group of 132 cases, 119 (90.1\%) cases were treated by intranasal endoscopic approach, while $13(9 \%)$ were treated by external approaches. Out of the 119 group that was treated by endoscopic approach, 95 were nasal polyposis patients who were treated by Functional Endoscopic Sinus Surgery. ${ }^{3}$, while 24 had other benign lesions of the nose and were treated by intranasal endoscopic assisted tumour excision.

24 Intranasal endoscopic assisted excision procedures $(10.6 \%)$ were done to 6 cases of Inverted papilloma and 7 cases of Nasopharyngeal Angiofibroma. This approach is also used in 4-Rhinosporidiosis, 3-Bleeding polypus and 1-Granuloma pyogenicum, 1-Meningoencephalocele; 1 Pleomorphic adenoma, 1-Angiomyxomatous polyp cases. ${ }^{4}$

6 lateral rhinotomy approaches $(3.78 \%)$ were performed in 5 cases of fibrous dysplasia, 1 case inverted papilloma.

Caldwell-Luc approach (2.27\%) was selected as a choice of approach to 3-maxillary mucoceles and 2 nasoalveolar cysts. ${ }^{5}$ Weber-Ferguson (1.32\%) combined with intranasal endoscopic assisted excision was elected as an approach in extensive 1-Nasopharyngeal angiofibroma.

Simple external excision (1.32\%) was used in 1- extranasal dermoid.

Three cases of nasopharyngeal angiofibroma are removed after arterial angiography and embolization to reduce intraoperative bleeding.

All the excised specimens were sent to the Department of Pathology to know the further nature and histopathology.

\section{DISCUSSION}

Till 1980, all the patients were operated only by naked eye through intranasal and extranasal approaches. After the invention of nasal endoscope, the scenario changed to intranasal approaches in many cases which were previously operated by extranasal approaches. Intranasal approaches preferred due to cosmetic reasons and precision in excision.

Among the 132 cases of the study 119 (90.1\%) cases were treated by intranasal endoscopic approach, while 13 (9\%) were treated by external approaches. Out of the 119 group that was treated by endoscopic approach 95 were nasal polyposis patients, while 24 had other benign lesions of the nose and were treated by intranasal endoscopic assisted tumour excision. Lateral rhinotomy is used in 6 cases, which includes in fibrous dyplasia-5 and 1-inverted papilloma.

95 (71.96\%) Functional Endoscopic Sinus Surgeries out of 132 were done for 95 cases of Nasal Polyposis, which includes 6 cases of recurrent nasal polyposis that underwent surgery outside after giving necessary pre-operative medical treatment to control infection and allergy. Thus, the FESS was the commonest and the foremost surgical procedure in approaches for benign mass lesions of the nose. ${ }^{6}$

In the remaining 37 surgeries, the Intranasal Endoscopic Assisted Excision-24 (18.18\%) which occupied second position was used in Nasopharyngeal Angiofibroma 7, Inverted Papilloma 6, rhinosporidiosis 4, bleeding polyposis 3, granuloma pyogenicum 1 , angiomyxomatous polyp 1 , pleomorphic adenoma 1 and meningoencephalocele 1 .

Lateral rhinotomy-6 (4.54\%) performed in fibrous dysplasia-5 and Inverted Papilloma-1, Caldwell-Luc approach - 5 (3.78\%) for maxillary mucocele 3 and nasoalveolar cyst 2 . The least common approaches used are Weber-Ferguson's - 1 $(1.32 \%)$ for extensive nasopharyngeal angiofibroma 1 and external simple excision - $1(1.32 \%)$ for external nasal dermoid 1.

The Cadaver dissection facility with cooperation of both Anatomy and Forensic Medicine Departments has brought about the widespread use of Intranasal Endoscopic methods leaving extranasal approaches to meagre cases.

We have not come across any case to use Midfacial degloving approach. ${ }^{7}$

\section{CONCLUSION}

Nasal polyposis is the commonest benign mass lesion of the nose. Hence, functional endoscopic sinus surgery is occupying the peak position among the procedures for benign mass lesions of the nose and it is a simple, safe procedure securing early recovery. ${ }^{8}$ Intranasal endoscopic-assisted excision took the second place as the next common lesions are nasopharyngeal angiofibroma, inverted papilloma and others. In the third position was lateral rhinotomy used mostly in fibrous dysplasia, while Caldwell-Luc approach was used for mucocele and nasoalveolar cyst. Weber-Ferguson approach on excision of extensive nasopharyngeal angiofibroma and simple external excision for dermoid of the nose were used rarely.

This suggests the need of CT scan, MRI scan and arteriography and embolization facility in Outpatient Department and gadgets like nasal endoscopes, HD cameras, Microdebriders to Operation theatres in all district headquarters hospitals to improve the quality of service to the patients. 


\section{REFERENCES}

1. Maran AGD, Lund VJ, Mackay IS, et al. Endoscopic sinus surgery. Report of royal college of surgeons of Edinburgh 1993.

2. Freedman HM, Kern EB. Complications of intranasal ethmoidectomy: a review of 1,000 consecutive operations. Laryngoscope 1979;89(3):421-34.

3. Kennedy DW, Zinreich SJ, Rosenbaum AE, et al. Functional endoscopic sinus surgery. Theory and diagnostic evaluation. Archives of otolaryngology 1985;111(9):576-82.

4. Mourie EJ. Traitement des tumours malignes primitive de'l'ethmoide revue de laryngologie, d'otologie et de. Rhinologie 1902;47:402-12.

5. Pentilla MA, Rautiainen ME, Pukander JS, et al. Endoscopic versus caldwell-luc approach in chronic maxillary sinusitis: comparison of symptoms at one- year follow up. Rhinology 1994;32(4):161-5.

6. Wigand ME. Endoscopic surgery of the paranasal sinuses and anterior skull base. Stuttgart: Georg Thieme Verlag 1990.

7. Casson PR, Bannono PC, Converse JM. The midface degloving procedure. Plastic and reconstructible surgery 1954;53:102-3.

8. Brwne JP, Hopkins C, Slack R, et al. Health related quality of life after polypectomy with or without additional surgery. Laryngoscope 2006;116(2):297-302. 